\title{
Fuzzy Sliding Mode Control Method for AUV Buoyancy Regulation System
}

\author{
Wende Zhao, ${ }^{1}$ Decheng Wang, ${ }^{1}$ Zhenzhong Chu $\mathbb{D}^{2},{ }^{2}$ and Mingjun Zhang $\mathbb{D}^{1}$ \\ ${ }^{1}$ College of Mechanical and Electrical Engineering, Harbin Engineering University, Harbin 150001, China \\ ${ }^{2}$ Logistics Engineering College, Shanghai Maritime University, Shanghai 200135, China
}

Correspondence should be addressed to Mingjun Zhang; zhangmingjun@hrbeu.edu.cn

Received 22 July 2021; Revised 24 September 2021; Accepted 19 October 2021; Published 10 November 2021

Academic Editor: Kalyana C. Veluvolu

Copyright (c) 2021 Wende Zhao et al. This is an open access article distributed under the Creative Commons Attribution License, which permits unrestricted use, distribution, and reproduction in any medium, provided the original work is properly cited.

This paper investigates the control problem of the buoyancy regulation system for autonomous underwater vehicle (AUV). There are some problems to be considered in the oil-water conversion-based buoyancy regulation system, including the external seawater pressure, the pressure fluctuations, and the slow switching speed of the ball valve. The control accuracy of the buoyancy regulation under the traditional PID controller cannot meet the requirements of the project. In this paper, a fuzzy sliding mode control scheme is developed for the buoyancy regulation system to solve the abovementioned problems. At first, a mathematical model of the buoyancy regulation system is established, and the stability of the system is analyzed. Then, the sliding mode control algorithm is combined with the fuzzy system to improve the control accuracy. Finally, the pool-experiment results on a prototype show that the developed control scheme can meet the requirements of the control accuracy for the buoyancy regulation system.

\section{Introduction}

With the high-speed development of marine resources, autonomous underwater vehicle (AUV) is playing an increasingly important role [1-5]. For the large-depth heave motion of the AUV, it will consume a large amount of energy if the propeller-based drive is selected, while the buoyancy regulation system will provide positive/negative buoyancy by discharging/charging water to achieve unpowered heave [6-9]. Thus, the buoyancy regulation system will effectively reduce energy consumption [10]. Therefore, it is of great significance and practical value to investigate the AUV buoyancy regulation problem with the motion requirement in large range of depth.

The buoyancy regulation system for AUV mainly has two ways, including variable volume and variable weight [11-14]. At present, the variable weight-based buoyancy regulation system is most widely used in the underwater vehicle $[15,16]$, which realizes buoyancy regulation by discharging and charging seawater. "Shin kai 6500" manned submersible in [17] and "Jiao long" manned submersible in [16] both adopt a variable weight-based buoyancy regulation system. In general, the volume of a manned submariner is relatively large, and the accuracy requirement of buoyancy regulation is relatively low. In this paper, the buoyancy regulation system is studied for a small AUV. The features of the developed buoyancy regulation system include small flow rate and high accuracy of buoyancy regulation.

In order to realize charging and discharging of seawater under ocean environment with high external pressure, the seawater pump with high pressure is mostly used in the buoyancy regulation system of manned submariners. There are no existing products to simultaneously meet the requirements of high pressure and seawater pump with small flow for the buoyancy regulation system used in a small AUV. Therefore, the authors developed a buoyancy regulation system based on oil-water conversion in [18]. A lowpressure oil pump was used to drive the seawater booster pump to avoid the seawater pump with high pressure and small flow. Based on our previous work in [18], this paper investigates the control method for the buoyancy regulation system based on oil-water conversion so as to satisfy the control requirements of buoyancy regulation. 
At present, there are some existing research studies about control of the buoyancy regulation system. In [19], an observerbased control scheme was developed for the variable ballast system to achieve the hovering control of the underwater vehicle. In [20], a new type water hydraulic variable ballast system was designed for underwater vehicles and a generalized predictive controller was proposed for this system. In [21], flow rate control was introduced into the water hydraulic variable ballast system to improve the hovering performance of the underwater vehicle. It has been found in our previous experiments that the buoyancy regulation system itself has pressure fluctuations and the switching speed of the ball valve is slow. All of these factors directly affect the response speed and control accuracy of buoyancy regulation. In addition, it is difficult to obtain the accurate dynamic model of the buoyancy regulation system. The Takagi-Sugeno (T-S) fuzzy model is always used to tackle the control of nonlinear systems. For example, the Markov switching system is described by the T-S fuzzy model in [22, 23].

Based on the abovementioned consideration, fuzzy technique is applied to sliding mode control in this paper to avoid the use of the dynamic model and reject the external disturbance during the valve-based buoyancy regulation. The main contributions of this paper are presented as follows:

(1) buoyancy regulation system is designed based on oilwater conversion

(2) To address the pressure fluctuations and slow switching speed, a fuzzy logic-based sliding mode control is proposed for the buoyancy regulation system

(3) Simulation and experimental results are provided to show the effectiveness of the developed method

The remainder of this paper is as follows. Section 2 briefly introduces the buoyancy regulation system based on oil-water conversion for a small AUV. Then, the mathematical model of the buoyancy control system considering the external seawater pressure is established in Section 3, including the stability analysis of the system. In Section 4 , the traditional PID controller is applied on the buoyancy regulation system. The fuzzy sliding mode control scheme is developed and the simulation results and pool-experiment results are given in Section 5. Finally, conclusions and future research are drawn in Section 6.

\section{Buoyancy Regulation System Based on Oil- Water Conversion}

The charging and discharging process schematic diagram of the buoyancy regulation system based on oil-water conversion developed in this paper is shown in Figures 1(a) and 1 (b), respectively [18].

In Figure 1, the low-pressure gear pump in the oil circuit drives the seawater booster pump. Two tanks shall be mounted on the fore and aft of the AUV, respectively. The buoyancy regulation is achieved by charging/discharging seawater into the tanks.

The process of seawater charging is shown in Figure 1(a). Seawater passes through filter $\longrightarrow$ switching valve$\longrightarrow$ booster pump $\longrightarrow$ balance valve $\longrightarrow$ one-way valve$\longrightarrow$ on-off valve $\longrightarrow$ ballast tanks. The process of seawater discharging is shown in Figure 1(b). Seawater is discharged through the ballast tanks $\longrightarrow$ on-off valve $\longrightarrow$ switching valve $\longrightarrow$ booster pump $\longrightarrow$ balance valve $\longrightarrow$ one-way valve $\longrightarrow$ filter $\longrightarrow$ seawater.

The main technical indexes of the buoyancy regulation system include that the average flow is larger than $3 \mathrm{~L} / \mathrm{min}$ and the overshoot of seawater is within the range between $-0.2 \mathrm{~L}$ and $0.2 \mathrm{~L}$.

\section{Modeling and Stability Analysis of Buoyancy Regulation Control System}

In [6], the effect of the external seawater pressure on the motor speed and hydraulic power source is not considered during the modeling process. Thus, the model established in [18] cannot reflect the real working environment of AUV. Furthermore, the control accuracy of the buoyancy regulation system in the ocean environment is not satisfactory. Therefore, this section will establish the mathematical model of the buoyancy control system under the external seawater pressure.

3.1. Mathematical Model of the Buoyancy Regulation System. According to the principle of the buoyancy regulation system given in Figure 1, the motor, gear pump, booster pump, level meter, single valve, and tanks are identified. And then, the block diagram of the buoyancy regulation system is shown as Figure 2.

In Figure 2, $Q_{f}$ represents the desired water volume; $Q_{m}$ represents the actual water volume in the tank; $K_{u}$ is the proportional coefficient of the controller; $K_{\omega}$ is the feedback coefficient of the brushless DC motor; $K_{Q}$ is the flow gain coefficient; and $K_{q}$ represents the flow line loss coefficient.

In this paper, the superposition principle is adopted to obtain the transfer relationship between the desired water volume $Q_{f}$ and the real one $Q_{m}$. At first, when there is no external seawater pressure, the transfer function is obtained according to the control block diagram of the system [24]:

$$
\frac{Q_{m}(s)}{Q_{f}(s)}=\frac{K_{u} K_{q} W(s) D(s)}{1+K_{\omega} D(S)+K_{Q} K_{u} K_{q} W(s) D(s)} .
$$

According to equation (1), the influence of external seawater pressure load is superimposed, and the output flow at this time can be obtained as follows:

$$
Q_{m}(s)=\frac{0.4 K_{T} K_{u} q_{c t} Q_{f}(s)}{L_{a} J s^{2}+\left(r_{a} J+L_{a} B_{V}\right) s+\left(r_{a} B_{V}+k_{e} K_{T}\right)}-\frac{0.4\left(r_{a}+L_{a} s\right) p R_{p} s_{p} q_{c t}}{1.9 s\left[L_{a} J s^{2}+\left(r_{a} J+L_{a} B_{V}\right) s+\left(r_{a} B_{V}+k_{e} K_{T}\right)\right]}-\frac{\left(0.4 k_{1}+1.9 k_{2}\right) p}{1.9 s} .
$$




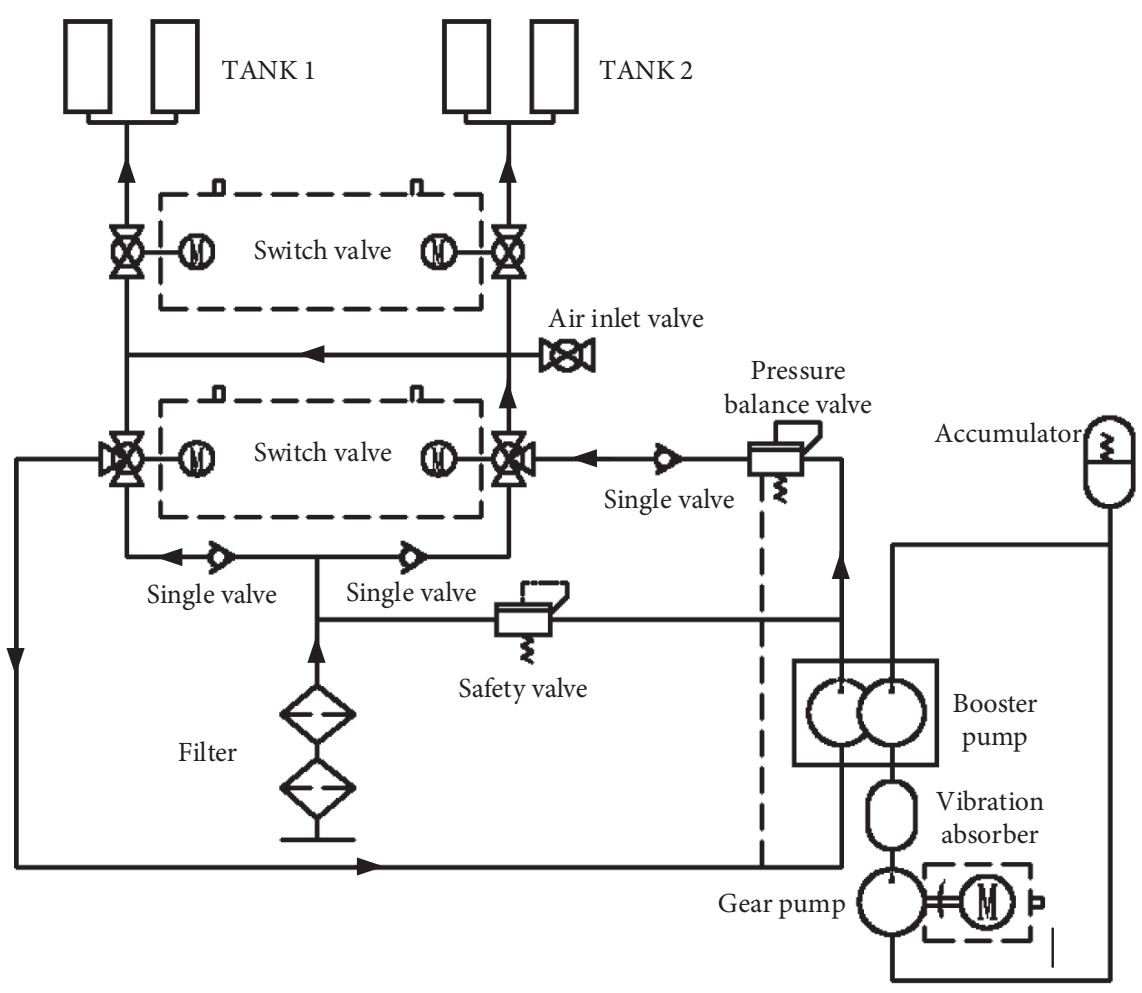

(a)

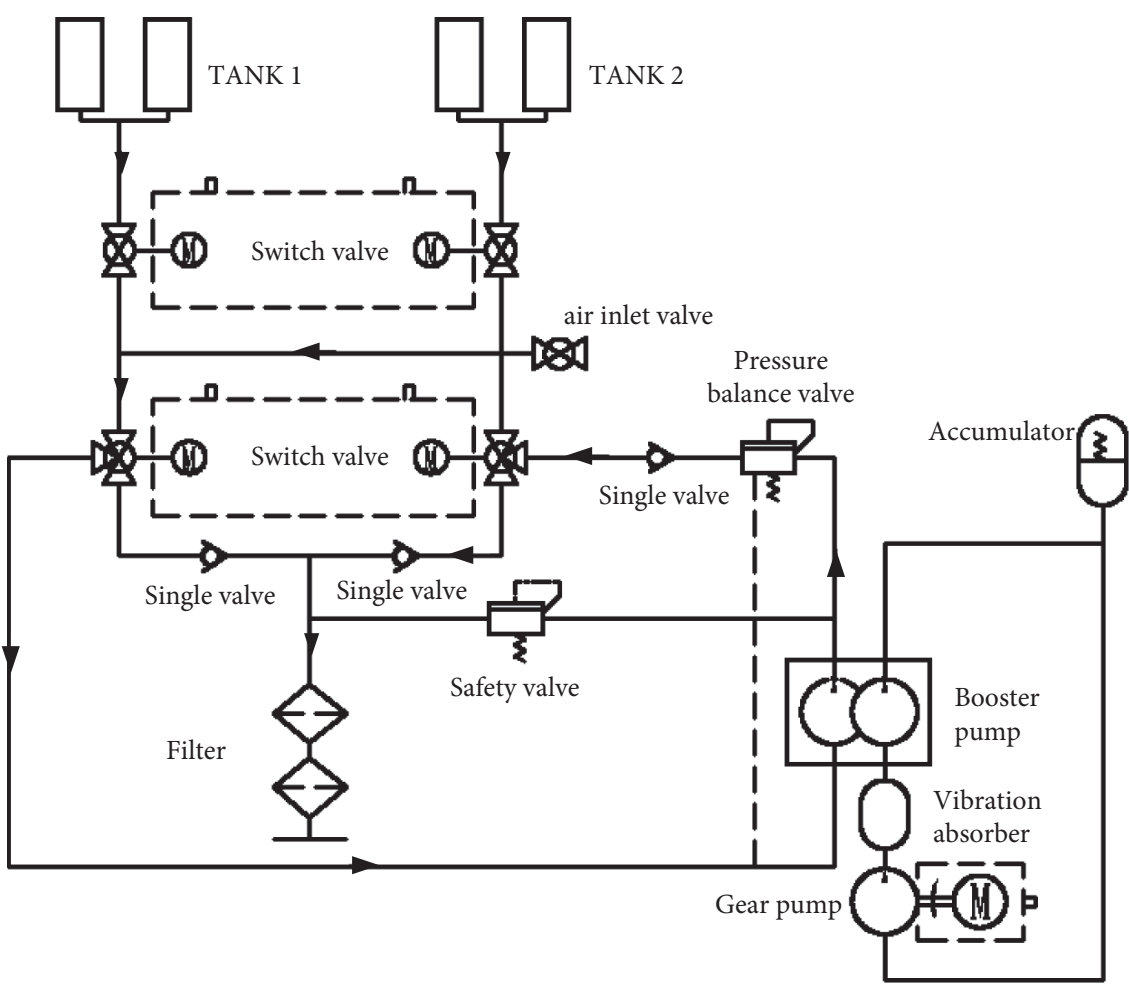

(b)

Figure 1: Schematic diagram of the buoyancy regulation system: (a) seawater charging process; (b) seawater discharging process.

Relevant parameters in equation (2) are briefly described as follows [24]. Motor torque coefficient $K_{T}$ is $0.477 \mathrm{~N} \cdot \mathrm{m} / \mathrm{A}$. The displacement of the gear pump $q_{c t}$ is $0.008 \mathrm{~L} / \mathrm{rev}$. The equivalent inductance $L_{a}$ is about $1 \times 10^{-3} \mathrm{H}$. Winding wire resistance $r_{a}$ is $0.8 \Omega$. The moment of inertia $J$ is $0.231 \times 10^{-3} \mathrm{~kg} \mathrm{~m}^{2}$. The viscosity friction coefficient $B_{V}$ is $7.33 \times 10^{-5} \mathrm{~N} \mathrm{~m}$ s. Line back EMF coefficient $k_{e}$ is 0.416 . The equivalent area of the gear pump $S_{p}$ is $1.05 \times 10^{-4} \mathrm{~m}^{2}$. The 


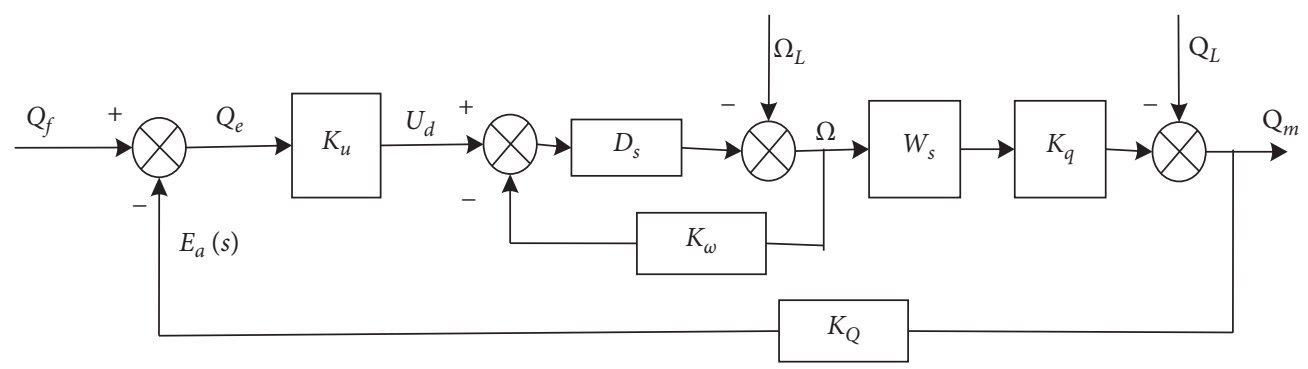

FIGURE 2: Block diagram of the buoyancy regulation system.

equivalent radius of the gear pump $R_{p}$ is $25 \times 10^{-3} \mathrm{~m}$; $p$ is the pressure of the seawater. The flow loss coefficient of the gear pump $k_{1}$ is 0.04 . The flow loss coefficient of the booster pump $k_{2}$ is 0.024 .

3.2. System Stability Analysis. According to the overall transfer function and the relevant parameters given in the previous subsection, the Simulink model of the system was established through MATLAB and the simulation was carried out, and the open-loop characteristics of the system are shown in Figure 3.

As can be seen from Figure 3, the gain margin of the open-loop system is infinite and the phase margin is $65.5^{\circ}$. In addition, the open-loop traversal frequency is $1.13 \times 10^{3} \mathrm{rad} /$ s. Therefore, it can be seen that the response speed of the system is high. The gain margin of the system is far greater than zero, and the phase margin is greater than the common engineering value $\left(40^{\circ} \sim 60^{\circ}\right)$. According to the Nyquist stability criterion, it can be judged that the system can meet the stability requirements in the closed-loop state.

\section{Problems Existing in the Traditional PID Controller}

It is found that there are pressure fluctuations in the load and outlet of the hydraulic valve when the hydraulic power source is working in the buoyancy regulation system. Under this scenario, the authors use the traditional PID control method to perform simulation-based analysis.

According to the transfer function and performance requirements of the project, the desired water volume is set as $5 \mathrm{~L} / \mathrm{min}$ and the regulation accuracy is set as $\pm 0.2 \mathrm{~L}$. Under the scenario, PID parameters are optimized in MATLAB, and then the detail parameters are set as $K_{p}=1.75, K_{i}=0.001$, and $K_{d}=0.018$.

For the case without pressure fluctuation, the simulation results for the zero load and $10 \mathrm{MPa}$ are shown in Figure 4, respectively.

As can be seen from Figure 4, the overshoot is about $0.2 \mathrm{~L}$ and the adjustment time is about $69 \mathrm{~s}$ when there is no load. For $10 \mathrm{MPa}$ pressure load, the overshoot is about $0.17 \mathrm{~L}$ and the adjustment time is about $74 \mathrm{~s}$.

In order to verify the anti-interference ability of the PID controller, random disturbance with the amplitude of $1 \mathrm{MPa}$ is added. The corresponding simulation results are shown in Figure 5.

As can be seen from Figure 6, when there exists pressure fluctuation in the buoyancy regulation system, the overshoot of the PID control method is about $0.25 \mathrm{~L}$, which does not meet the requirement of being less than $0.2 \mathrm{~L}$. For this reason, this paper studies the new control method.

\section{Buoyancy Regulation Based on Fuzzy Sliding Mode Method}

This section studies the fuzzy sliding mode control method. And then, the effectiveness of the developed control scheme is verified by simulation results and experiment result, respectively.

5.1. Fuzzy Sliding Mode Control Method. The fuzzy sliding mode control method has been widely used in other nonlinear systems [25-27]. In the control system, the sliding mode controller is used as the local controller, and the Sugeno fuzzy controller is used to link and combine the local controllers.

The structure diagram of the fuzzy sliding mode control for the buoyancy regulation system designed is shown in Figure 7.

Suppose that when the water quantity error is $e>1.5 \mathrm{~L}$, the motor control voltage $u$ is the maximum value; when the water quantity error is $e<0$, the control voltage $u$ is 0 , as shown in the following equation:

$$
u= \begin{cases}5 \mathrm{~V} & e>1.5 \mathrm{~L}, \\ 0 & e<0\end{cases}
$$

Assuming that the water quantity error is $-1.5 \mathrm{~L} \leq e \leq$ $1.5 \mathrm{~L}$, the fuzzy sliding mode controller is used to regulate the water quantity in the tanks. The distribution of water quantity deviation membership function is shown in Figure 8 .

The sliding mode surface is defined as $s=\dot{e}+\lambda_{i} e$ with positive constant $\lambda_{i}$. The sliding mode controller corresponding to the controller is distributed in different fuzzy regions, shown as follows: 

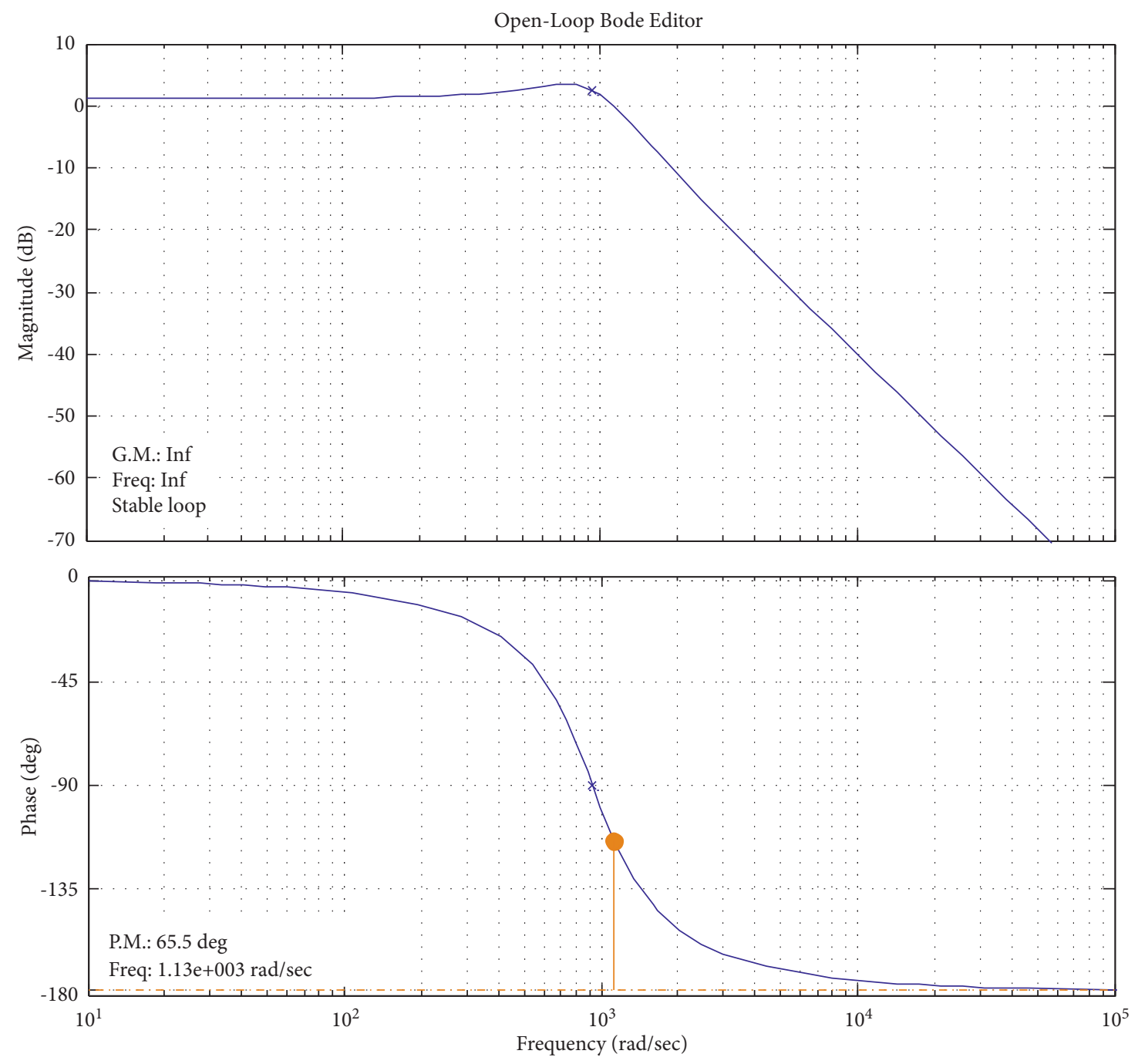

Figure 3: Open-loop bode diagram of the system.

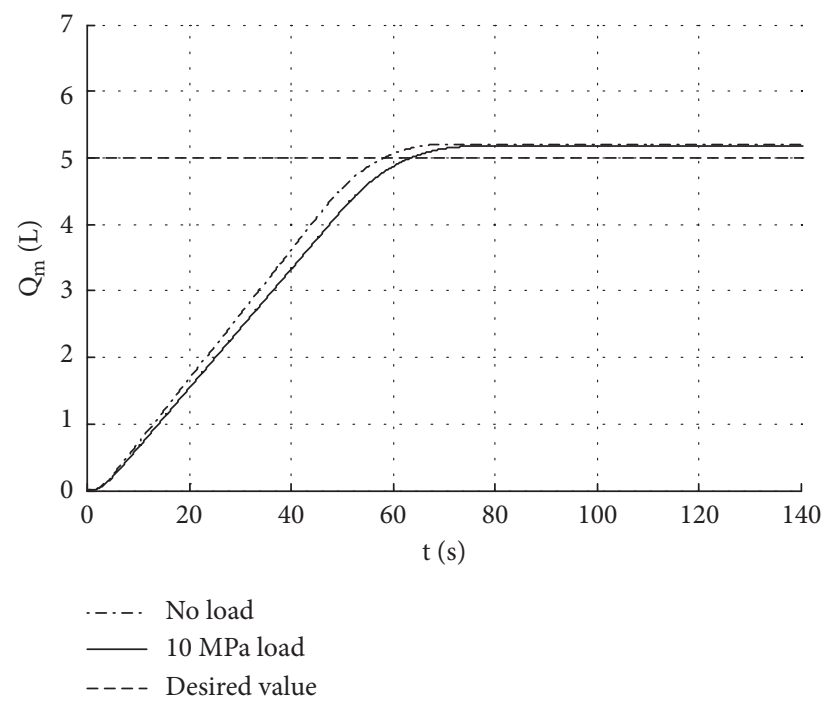

FIGURE 4: PID control system response curve without disturbances. 

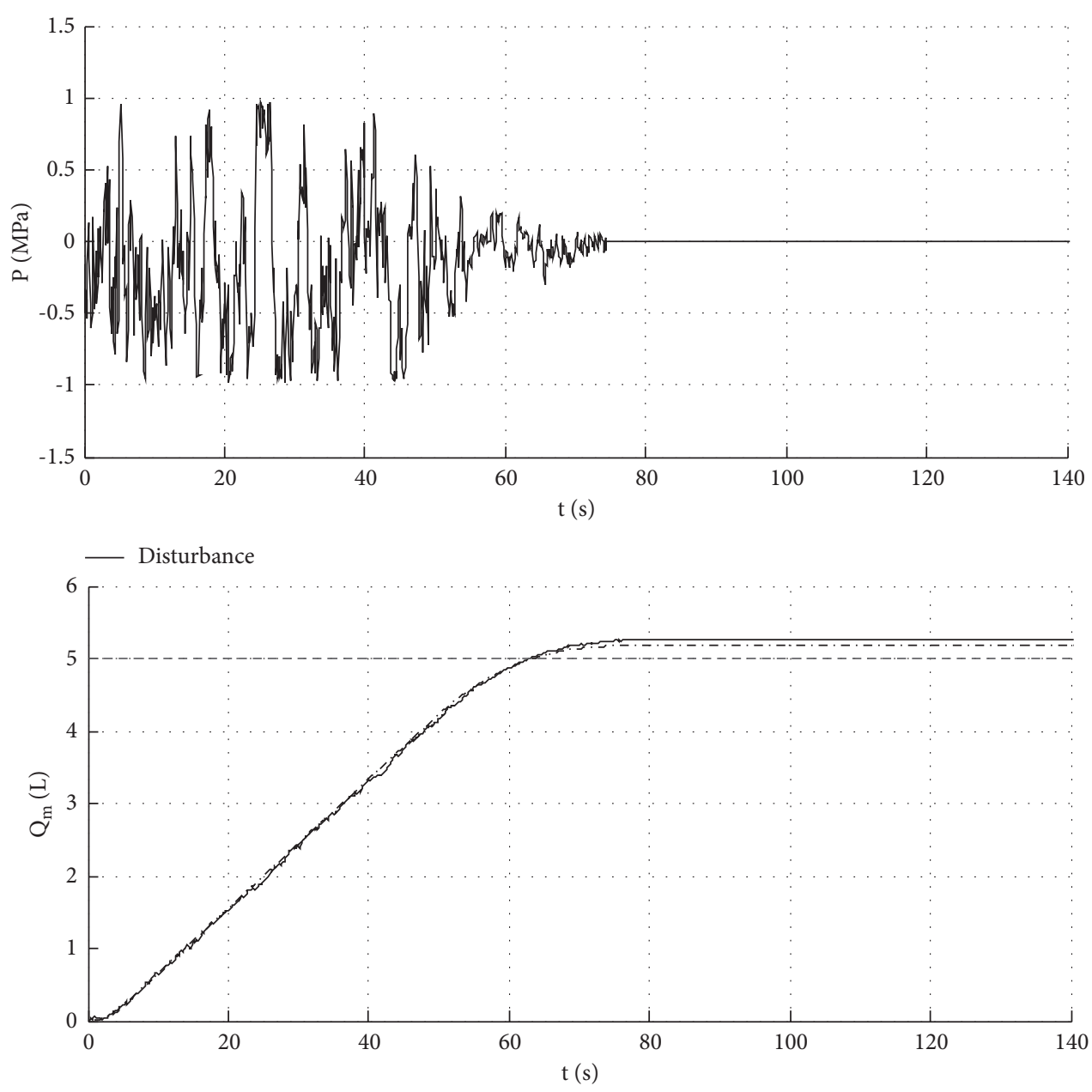

-.- No disturbance

_ Under disturbance

- - - Desired value

FIGURE 5: PID control system response curve with disturbance.

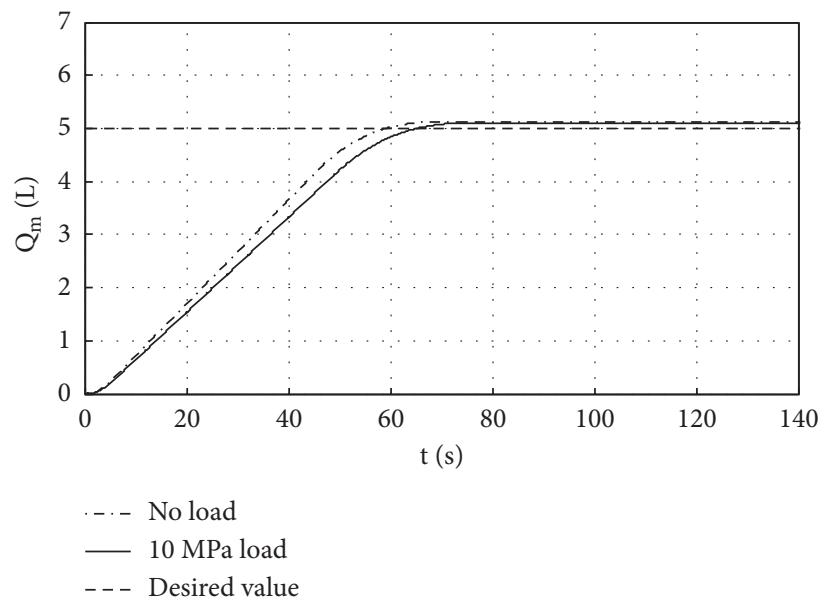

FIGURE 6: Response curve based on the fuzzy sliding mode controller. 


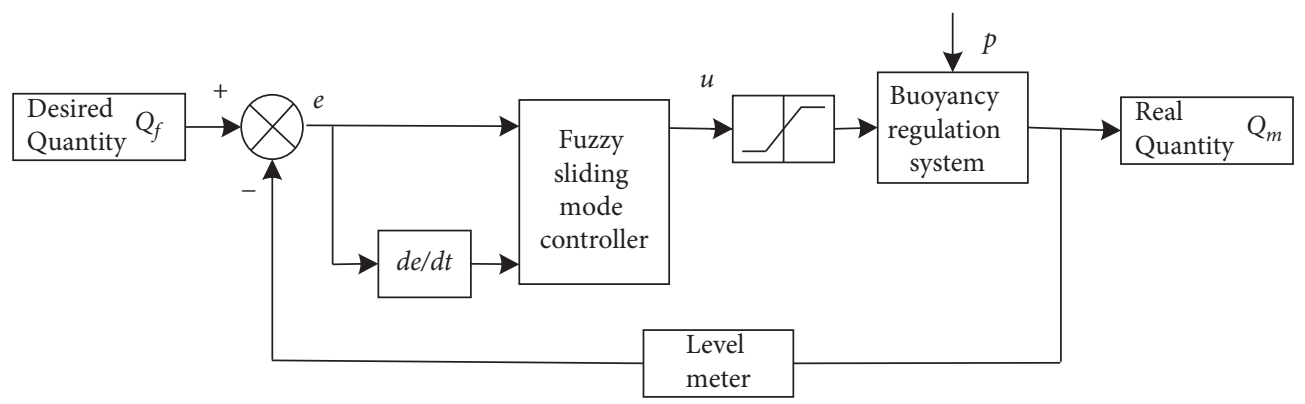

FIgURE 7: Block diagram of the fuzzy sliding mode controller.

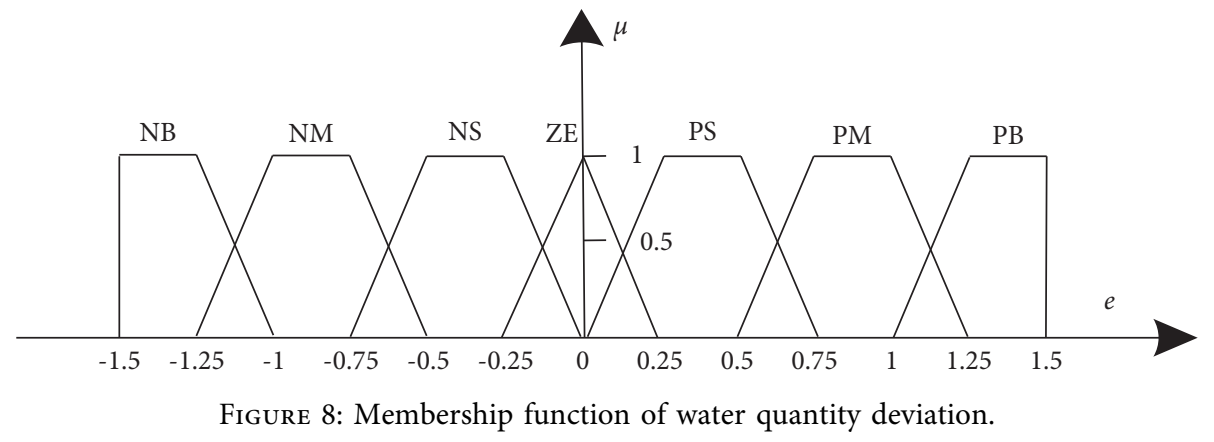

$$
\text { then } u_{i}= \begin{cases}-k \operatorname{sgn}(s) & \text { if } e \text { is } A_{i}, \\ -k \sin \omega_{i}(s) & -\frac{\pi}{2 \omega}<s \leq 0, \\ 0 & s>0,\end{cases}
$$

where $\lambda_{i}$ is the slope of the sliding line of the $i$ th rule, $\omega_{i}$ is the boundary layer thickness of rule $i$, and $u_{i}$ is the output of rule $i$ of the sliding mode fuzzy controller. Since the range of the control voltage $u$ is $[0 \mathrm{~V}, 5 \mathrm{~V}], k$ in equation (3) is set as $5 . A_{i}$ belong to the set (NB, NM, NS, ZE, PS, PM, PB), shown in Figure 8.

Then, the total control effort is given by

$$
u=\sum_{i=1}^{m} b_{i} u_{i}
$$

where $b_{i}=\mu_{A i}(e) / \sum_{j=1}^{m} \mu_{A_{j}}(e)$ and $\mu_{A i}(e)$ is the membership function of $e$ in the precomponent of the $i$ th rule.

The buoyancy regulation control system developed in this paper can only achieve one-way regulation. Here, the parameter adjustment method of sliding mode controller in [13] is adopted, and the specific control rules are shown in Table 1.

5.2. Simulation Verification. When there is no pressure fluctuation, the fuzzy sliding mode controller is applied to the buoyancy regulation system under the conditions of no pressure load and $10 \mathrm{MPa}$ pressure load, respectively, and the response curve of the system is shown in Figure 6.
To verify the anti-interference ability of the fuzzy sliding mode control algorithm, random disturbance with the amplitude of $1 \mathrm{MPa}$ is added for the case with $10 \mathrm{MPa}$. The simulation results obtained are shown in Figure 9.

For the convenience of comparison and analysis, the simulation results of the PID controller and the fuzzy sliding mode controller are summarized in Table 2.

As can be seen from Table 2, the buoyancy regulation system under the fuzzy sliding mode controller meets the requirements of the project, including the adjusting speed, control precision, and anti-interference ability.

\subsection{Experimental Verification}

5.3.1. Experimental Set-Up. The maximum voltage of the motor in the buoyancy regulation system is $5 \mathrm{~V}$. And the sampling frequency of the liquid level sensor is $0.1 \mathrm{~s}$. In this experiment, the desired water quantity is $10 \mathrm{~L}$. In addition, two cases are considered. Specifically, the first case is without any load, while the second case is with $10 \mathrm{MPa}$ load. The protype of the buoyancy regulation system is presented in Figure 10.

5.3.2. Experimental Results. The comparison experiments of the PID controller and the fuzzy sliding mode controller are carried out for the case without load and the case with $10 \mathrm{MPa}$, respectively. The response curves of water quantity control are shown in Figures 11 and 12.

For the convenience of comparative analysis, the above experimental data are converted into a table, as shown in Table 3.

As can be seen from Table 3, for the case with no load, the adjustment time of the fuzzy sliding mode controller is $124 \mathrm{~s}$, 
TABLE 1: Rules of the fuzzy sliding mode controller.

\begin{tabular}{lcc}
\hline Water quantity deviation $e$ & Boundary layer thickness $\omega_{i}$ & Slope of slide line $\lambda_{i}$ \\
\hline PB & 0.2 & 0.02 \\
PM & 0.3 & 0.04 \\
PS & 0.35 & 0.05 \\
ZE & 0.5 & 0.08 \\
NS & - & - \\
NM & - & - \\
NB & - & - \\
\hline
\end{tabular}
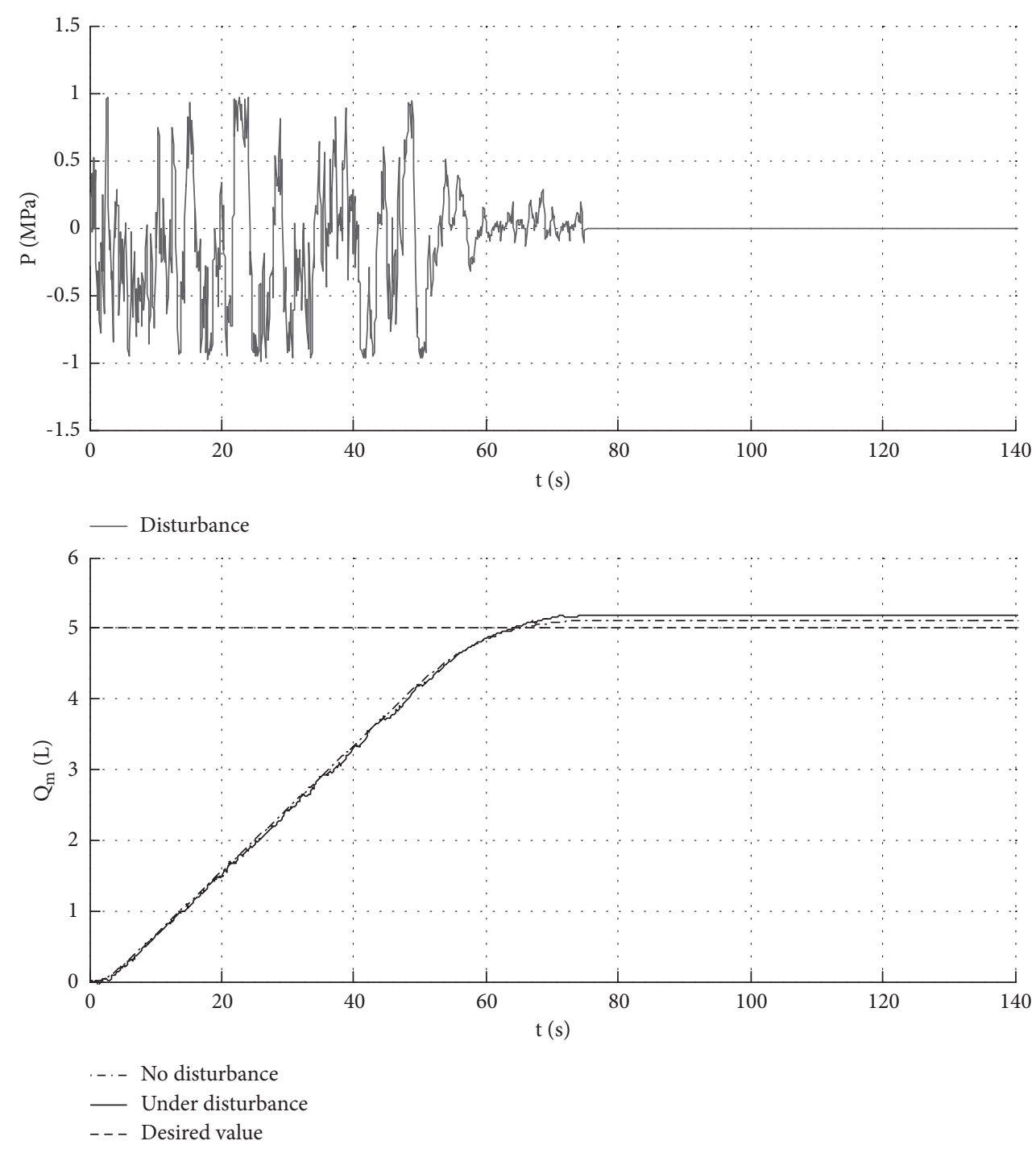

FIgURE 9: Response curve of the fuzzy sliding mode controller under disturbance.

TABLE 2: Comparison of simulation results under different controllers.

\begin{tabular}{|c|c|c|c|c|c|c|}
\hline \multirow{3}{*}{ The control method } & \multicolumn{4}{|c|}{ No random interference } & \multicolumn{2}{|c|}{ Random interference (amplitude is $1 \mathrm{MPa}$ ) } \\
\hline & \multicolumn{2}{|c|}{$\begin{array}{l}\text { The average flow rate } \\
(\mathrm{L} / \mathrm{min})\end{array}$} & \multicolumn{2}{|c|}{ Overshoot (L) } & \multirow{2}{*}{$\begin{array}{l}\text { The average flow rate }(\mathrm{L} / \mathrm{min}) \\
10 \mathrm{MPa} \text { load }\end{array}$} & \multirow{2}{*}{$\begin{array}{l}\text { Overshoot amount (L) } \\
10 \mathrm{MPa} \text { load }\end{array}$} \\
\hline & No load & $10 \mathrm{MPa}$ load & No load & $10 \mathrm{MPa}$ load & & \\
\hline PID control & 4.34 & 4.05 & 0.2 & 0.17 & 3.95 & 0.25 \\
\hline Fuzzy sliding mode control & 4.48 & 4.10 & 0.12 & 0.10 & 4.00 & 0.19 \\
\hline
\end{tabular}



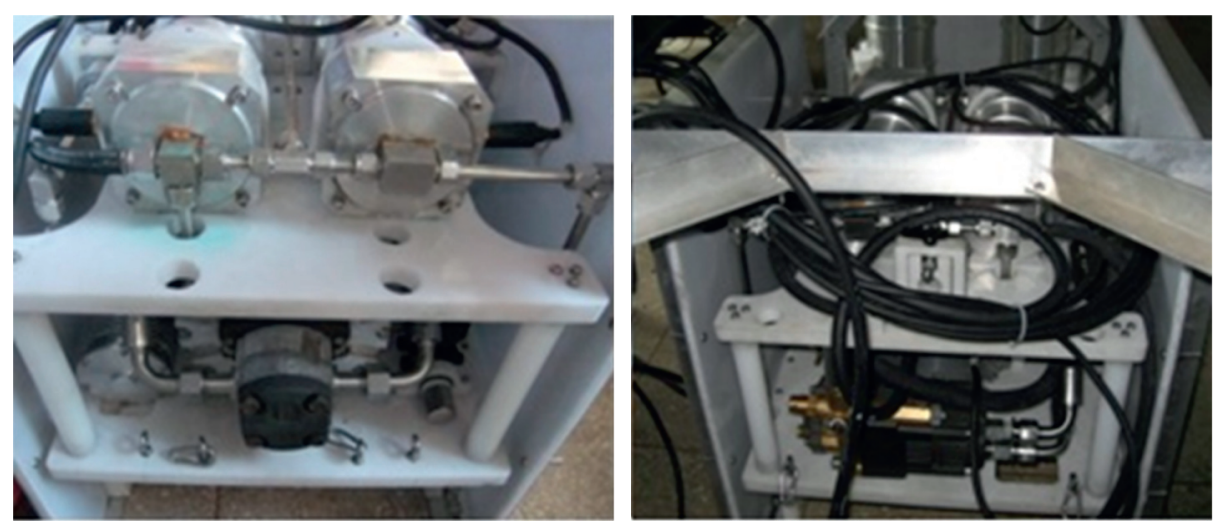

FIGURe 10: Prototype of the buoyancy regulation system.
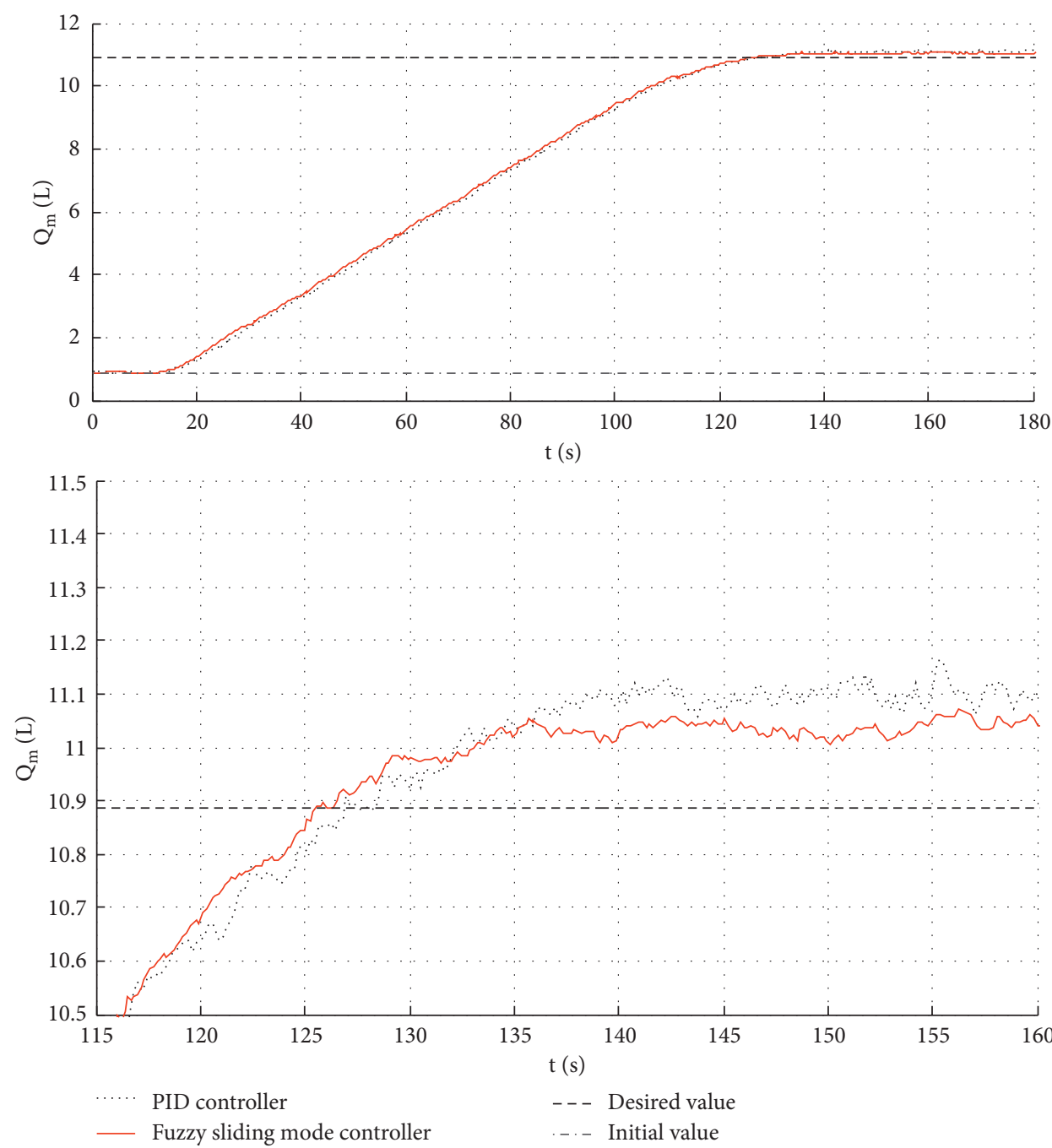

FIGURE 11: Experimental results of different control methods under no load.

which is $4.0 \%$ faster than that of the PID controller. The overshoot of the fuzzy sliding mode control method is $0.17 \mathrm{~L}$, which is $22.7 \%$ higher than that of the PID method. The adjustment time of the fuzzy sliding mode control method is $142 \mathrm{~s}$ for the case with $10 \mathrm{MPa}$ load, which is about $1.9 \%$ faster than that of the PID controller. The overshoot of the sliding mode fuzzy control method is $0.20 \mathrm{~L}$, while the corresponding result is $0.3 \mathrm{~L}$ under the PID controller. The flow rate of the sliding mode fuzzy control method is higher than $4 \mathrm{~L} / \mathrm{min}$ through the calculation of the liquid level sensor information of the water storage cylinder. It can be seen from the experimental results that the fuzzy sliding 

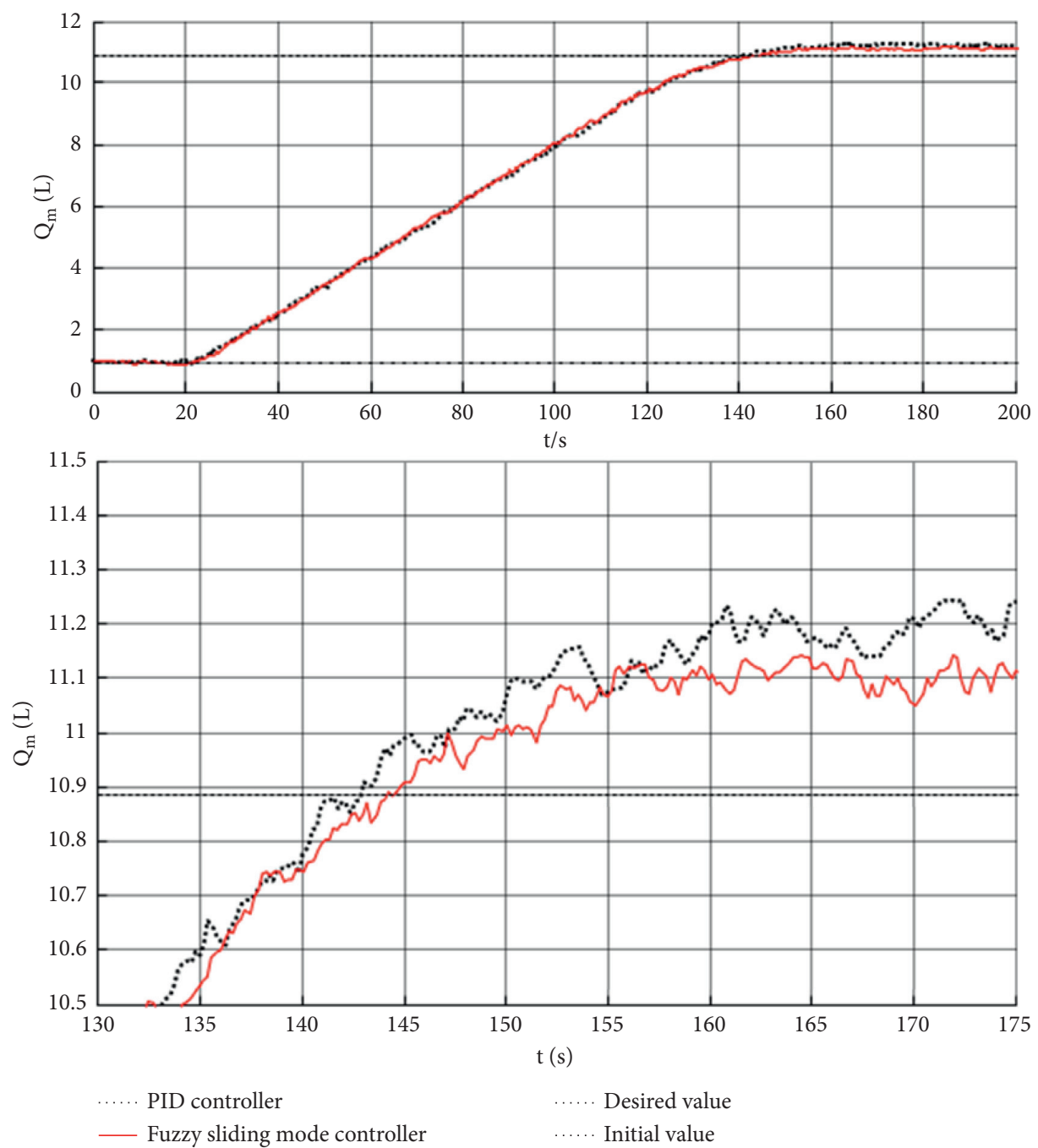

FIGURE 12: Experimental results of different control methods under $10 \mathrm{MPa}$ load.

TABLE 3: Experimental results of different controllers.

\begin{tabular}{lcccc}
\hline & \multicolumn{2}{c}{ No load } & \multicolumn{2}{c}{10 MPa load } \\
& Adjustment time (s) & Overshoot amount (L) & Adjustment time (s) & Overshoot amount (L) \\
\hline PID control & About 130 & 0.22 & About 145 & 0.3 \\
Sliding mode fuzzy control & About 124 & 0.17 & About 142 & 0.2 \\
\hline
\end{tabular}

mode control can meet the requirements of the average flow being larger than $3 \mathrm{~L} / \mathrm{min}$ and the overshoot being within the range of $\pm 0.2 \mathrm{~L}$ under the different conditions.

\section{Conclusion}

This paper investigates the control problem for the buoyancy regulation system. And a fuzzy sliding mode control scheme is applied to the buoyancy regulation system. According to the experiment results, it is shown that the flow rate is higher than $4 \mathrm{~L} / \mathrm{min}$ under the developed control scheme, and the overshoots are $0.17 \mathrm{~L}$ and $0.20 \mathrm{~L}$ for the case without load and with $10 \mathrm{MPa}$ load, respectively. The experiment results satisfy the performance requirements, i.e., the average flow being larger than $3 \mathrm{~L} / \mathrm{min}$ and the overshoot is within the range of $\pm 0.2 \mathrm{~L}$.
The developed controller requires the complete information of the system. In future research, we need to investigate control scheme for the buoyancy regulation system with uncomplete information.

\section{Appendix}

The stability analysis of the closed-loop system under the developed control scheme is presented as follows.

The dynamic model of the buoyancy regulation system can be rewritten as the following form according to equation (2):

$$
\ddot{Q}=f(Q, \dot{Q}, t)+b u(t)+d(t),
$$

where $f(Q, \dot{Q}, t)$ is the nonlinear function term; $b$ is the positive constant; and $d(t)$ is the general disturbances, including modeling uncertainty and external disturbance. 
The Lyapunov function is defined as $V=0.5 s^{2}$, and the time derivative of the function $V$ can be rewritten as the following form:

$$
\dot{V}=s \dot{s}=f(Q, \dot{Q}, t) s+\text { bus }+d(t) s+\lambda_{i} \dot{e s} .
$$

When $s \leq-\pi / 2 \omega$, equation (A.2) can be rewritten as the following form, after submitting the control law (5):

$$
\dot{V}=f s+b s\left[-\sum_{i=1}^{m} \frac{\mu_{A i}(e)}{\sum_{j=1}^{m} \mu_{A_{j}}(e)} k \operatorname{sgn}(s)\right]+\mathrm{d} s+\lambda \dot{e} s=f s-b k|s|+\mathrm{d} s+\lambda \dot{e} s=|s|(|f+d+\lambda \dot{e}|-b k) .
$$

Since $k$ is the control gain, if the authors select a proper value of $k$ which satisfies $k>1 / b|f+d+\lambda \dot{e}|$, one can easily obtain that $\dot{V}<0$. Therefore, under the control law (5), the absolute value of the sliding mode surface can be less than $\pi / 2 \omega$.

\section{Data Availability}

The data used to support the findings of this study are available from the corresponding author upon request.

\section{Conflicts of Interest}

The authors declare that there are no conflicts of interest.

\section{Acknowledgments}

This work was supported by National Natural Science Foundation of China under Grant 51839004.

\section{References}

[1] I. Masmitja, J. Navarro, S. Gomariz et al., "Mobile robotic platforms for the acoustic tracking of deep-sea demersal fishery resources," Science Robotics, vol. 5, no. 48, Article ID eabc3701, 2020.

[2] T. Liu, Y. L. Hu, and H. Xu, "Deep reinforcement learning for vectored thruster autonomous underwater vehicle control," Complexity, vol. 2021, Article ID 6649625, 25 pages, 2021.

[3] J. Cui, H. Sun, and J. Lu, "Fixed-time trajectory tracking control of autonomous surface vehicle with model uncertainties and disturbances," Complexity, vol. 2020, Article ID 3281368, 10 pages, 2020.

[4] X. Liu, M. Zhang, and S. Wang, "Adaptive region tracking control with prescribed transient performance for autonomous underwater vehicle with thruster fault," Ocean Engineering, vol. 196, Article ID 106804, 2020.

[5] C. Yu, X. Xiang, P. A. Wilson, and Q. Zhang, "Guidance-errorbased robust fuzzy adaptive control for bottom following of a flight-style AUV with saturated actuator dynamics," IEEE Transactions on Cybernetics, vol. 50, no. 5, pp. 1887-1899, 2020.

[6] H. Zhi, P. Zhou, Y. Chen et al., "Buoyancy regulation strategy for underwater profiler based on adaptive genetic algorithm," Journal of Marine Science and Engineering, vol. 9, no. 1, 2021.

[7] Y. Huang, Z. Wang, J. Yu, A. Zhang, J. Qiao, and H. Feng, "Development and experiments of the passive buoyancy balance system for sea-whale 2000 AUV," in Proceedings of the Oceans 2019-Marseille, June 2019.

[8] S. Song, T.-S. Kim, and M. Sung, S.-C. Yu, Attitude control of AUV using multiple buoyancy engines for exploration and water column profiling," in Proceedings of the 2018 IEEE/Oes Autonomous Underwater Vehicle Workshop, November 2018.

[9] M. Sung and S. C. Yu, "Balloon AUV: seawater sampling AUV using active buoyancy control," in Proceedings of the 2018 IEEE/Oes Autonomous Underwater Vehicle Workshop, November 2018.

[10] A. V. Medvedev, V. V. Kostenko, and A. Y. Tolstonogov, "Depth control methods of variable buoyancy AUV," in Proceedings of the 2017 IEEE Underwater Technology, February 2017.

[11] C. Thangavel, P. Muthuvel, S. Maurya, and T. Sudhakar, "Design and development of non-rotary propulsion for autonomous underwater vehicles," in Proceedings of the 2015 IEEE Underwater Technology, February 2015.

[12] M. G. Joo and Z. Qu, "An autonomous underwater vehicle as an underwater glider and its depth control," International Journal of Control, Automation and Systems, vol. 13, no. 5, pp. 1212-1220, 2015.

[13] Z. Y. Wang, J. Yu, A. Zhang, Z. Sun, and S. Kang, "Development and experiments of the buoyancy adjusting system of long-range AUV," in Proceedings of the 2018 Oceans-Mts/ IEEE Kobe Techno-Oceans, May 2018.

[14] T. S. Kim, J. Kim, and S.-C. Yu, "Design of a Buoyancy Controllable AUV by changing volume for data collection in the water column," in Proceedings of the IEEE/Oes Autonomous Underwater Vehicle Workshop, November 2018.

[15] X. Zhu, B. Song, G. Xu, and S. Yang, "Research on landing strategy and influencing factors of an autonomous underwater vehicle with supporting mechanism," Shanghai Jiaotong Daxue Xuebao/Journal of Shanghai Jiaotong University, vol. 51, no. 10, pp. 1241-1251, 2017.

[16] B.-B. Pan, W.-C. Cui, C. Ye, and Z.-Y. Liu, "Development of the unpowered diving and floating prediction system for deep manned submersible "JIAOLONG"," Chuan Bo Li Xuel Journal of Ship Mechanics, vol. 16, no. 1-2, pp. 58-71, 2012.

[17] S. Takagawa, "Advanced technology used in Shinkai 6500 and full ocean depth ROV Kaiko," Marine Technology Society Journal, vol. 29, no. 3, pp. 15-25, 1995.

[18] W. Zhao, J. Zhang, Y. Zhao, and D. Wang, "Development of a deep-sea buoyancy regulating system," Harbin Gongcheng Daxue Xuebao/Journal of Harbin Engineering University, vol. 36, no. 9, pp. 1269-1275, 2015.

[19] A. Bi and Z. Feng, "Composite hovering control of underwater vehicles via variable ballast systems," Journal of Marine Science and Technology, vol. 25, no. 3, pp. 659-666, 2019.

[20] Y. Liu, X. Zhao, D. Wu, D. Li, and X. Li, "Study on the control methods of a water hydraulic variable ballast system for submersible vehicles," Ocean Engineering, vol. 108, pp. 648661, 2015.

[21] X. Zhao, Y. Liu, M. Han, D. Wu, and D. Li, "Improving the performance of an AUV hovering system by introducing low- 
cost flow rate control into water hydraulic variable ballast system," Ocean Engineering, vol. 125, pp. 155-169, 2016.

[22] J. Cheng, H. Yan, J. H. Park, and G. Zong, "Output-feedback control for fuzzy singularly perturbed systems: a nonhomogeneous stochastic communication protocol approach," IEEE Transactions on Cybernetics, 2021.

[23] J. Cheng, W. Huang, J. H. Park, and J. Cao, "A hierarchical structure approach to finite-time filter design for fuzzy Markov switching systems with deception attacks," IEEE Transactions on Cybernetics, 2021.

[24] J. Zhang, Research on Sea Buoyancy Regulating System and Control Technology, Harbin Engineering University, Harbin, China, 2014.

[25] Y. Zhang, Q. Zhang, J. Zhang, and Y. Wang, "Sliding mode control for fuzzy singular systems with time delay based on vector integral sliding mode surface," IEEE Transactions on Fuzzy Systems, vol. 28, no. 4, pp. 768-782, 2020.

[26] P. J. Prieto-Entenza, N. R. Cazarez-Castro, L. T. Aguilar, S. L. Cardenas-Maciel, and J. A. Lopez-Renteria, "A Lyapunov analysis for mamdani type fuzzy-based sliding mode control," IEEE Transactions on Fuzzy Systems, vol. 28, no. 8, pp. 1887-1895, 2020.

[27] X. Su, Y. Wen, P. Shi, S. Wang, and W. Assawinchaichote, "Event-triggered fuzzy control for nonlinear systems via sliding mode approach," IEEE Transactions on Fuzzy Systems, vol. 29, no. 2, pp. 336-344, 2021. 